\title{
FATORES DE INSERÇÃO NOS MERCADOS LOCAIS SOB A ÓTICA DOS FEIRANTES
}

\author{
INSERTION FACTORS IN LOCAL MARKETS FROM \\ THE PERSPECTIVE OF TRADE COMPANIES
}

\section{Eluane Parizotto Seidler}

Mestra em Agronegócios pela Universidade Federal de Santa Maria (Palmeira das Missões/Brasil). Professora Substituta no Departamento de Administração na Universidade Federal de Santa Maria (Palmeira das Missões/Brasil).

E-mail: eluanepseidler@gmail.com

\section{Tanice Andreatta}

Doutora em Desenvolvimento Rural pela Universidade Federal do Rio Grande do Sul (Porto Alegre/Brasil).

Professora no Departamento de Ciências Econômicas e no Programa de Pós-Graduação em Agronegócios na Universidade

Federal de Santa Maria (Palmeira das Missões/Brasil).

E-mail: tanice.andreatta@ufsm.br

\section{Luiz Fernando Fritz Filho}

Doutor em Desenvolvimento Rural pela Universidade Federal do Rio Grande do Sul (Porto Alegre/Brasil).

Professor e pesquisador (Titular III) e Coordenador do Programa de Pós-graduação em Administração na Universidade de Passo Fundo (Passo Fundo/Brasil).

E-mail: fritz@upf.br

Recebido em: 8 de janeiro de 2021

Aprovado em: 22 de março de 2021

Sistema de Avaliação: Double Blind Review

RGD | v. 18| n. 2 | p. 154-177 | mai./ago. 2021

DOI: https://doi.org/10.25112/rgd.v18i2.2454 


\section{RESUMO}

O presente estudo tem como objetivo analisar os fatores de inserção nos mercados locais, sob a ótica dos feirantes que comercializam na Feira Municipal dos Produtores Rurais de Passo Fundo-RS. A investigação empírica e a coleta de dados foram realizadas por intermédio de aplicação de um roteiro de pesquisa estruturado. Foram entrevistados 47 feirantes, nos meses de maio e setembro de 2018. Em relação à estrutura da feira, ressalta-se aspectos antes apontados como gargalos (questão sanitária e acessibilidade) que foram solucionados com a mudança do espaço, embora haja dificuldades em relação aos estacionamentos. Foi identificado três tipos de feirantes. Predominam feirantes que comercializam produtos "in natura", seguidos daqueles que comercializam produtos agroindustrializados, em que a produção é, majoritariamente, realizada pelos próprios feirantes, nas respectivas unidades de produção; o terceiro tipo é configurado por feirantes que atuam somente na comercialização, ou seja, são intermediários e uma agricultora que comercializa artesanato. Os resultados corroboram com a literatura sobre a relevância de relações econômicas e, sobretudo, sociais, construídas no âmbito das cadeias agroalimentares curtas como rastreabilidade informal, confiança, qualidade e origem dos alimentos. Entre as motivações para atuarem nesse ramo está a reprodução econômica e social dos feirantes e suas respectivas famílias. Para estudos futuros, sugere-se ter a contrapartida da pesquisa, sob a óptica dos consumidores.

Palavras-chave: Agricultura familiar. Cadeias curtas de abastecimento alimentar. Comercialização. Feira.

\section{ABSTRACT}

This study aims to analyze the insertion factors in local markets, from the perspective of the fairgoers who sell at the Municipal Farmers' Fair of Passo Fundo-RS. Empirical investigation and data collection were performed through the application of a structured research script. Forty-seven fairchildren were interviewed in May and September 2018. Regarding the structure of the fair, we highlight aspects previously pointed out as bottlenecks (sanitary issue and accessibility) were solved with the change of space, although there are difficulties in relation to parking lots. Three types of fairmen have been identified. There is a predominance of fairs that sell "in natura" products, followed by those that sell agro-industrialized products, where production is mostly carried out by the fairchildren themselves, in the respective production units; the third type is configured by fairgoers who act only in marketing, that is, they are intermediaries and a farmer who sells handicrafts. The results corroborate the literature on the relevance of economic relations, especially social relations built within the scope of short agri-food chains such as informal traceability, confidence, quality and origin of food. The motivations to work in this branch are the economic and social reproduction of the fairgoers and their respective families. For future studies, it is suggested to have the counterpart of the research, from the perspective of consumers.

Keywords: Family farming. Short food supply chains. Commercialization. Market. 


\section{INTRODUÇÃO}

O resgate de práticas de produção artesanais e conhecimentos tradicionais têm valorizado os produtos "caseiros", coloniais, com menor utilização de agrotóxicos, diferenciados e de qualidade oriundos, na maioria das vezes, da agricultura familiar. Esses produtos tem cada vez mais adquirido espaço e conquistado consumidores que buscam alimentos mais saudáveis, vindos "direto da terra" e que valorizam a atividade do agricultor.

O papel que mais tem se destacado na agricultura familiar refere-se à agregação de valor à produção agrícola e à transformação desta, em produtos e serviços que circulam em nível local. Esta é a realidade de muitos Estados e municípios do Brasil, em que o dinamismo social e econômico depende da agricultura familiar (SCARABELOT; SCHNEIDER, 2012).

Comisso, abusca deum modelo de desenvolvimento queseja capaz de implementaraautossuficiência de produtos processados e in natura nos mercados locais, que valorize as regiões e territórios, preze pelas ações cooperativas e associativas, assim como, a agregação de valor nas propriedades rurais, se tornam indispensáveis para a sustentação da agricultura familiar (JUNIOR; TRENTIN, 2006).

As "novas" cadeias de fornecimento de alimentos, as cadeias alternativas ou curtas, são importantes portadoras para criar novas ligações entre a agricultura e a sociedade, produtores e consumidores, pois, possibilitam trazer os consumidores para mais perto das origens de seus alimentos, além de, proporcionar contato mais direto entre os agricultores e os usuários finais de seus produtos (RENTING; MARSDEN; BANKS, 2003; ROSSI, 2012).

Nesse sentido, tanto o desenvolvimento de novas formas de produção, assim como, o consumo alimentar, estão vinculados ao processo mais geral denominado de "virada da qualidade" (quality turn). Onde a questão agroalimentar passa por um movimento que leva a direção da qualidade baseada na confiança, na tradição local e em novas formas de organização econômica (ROSSI, 2012). Assim, a inserção dos agricultores nos circuitos agroalimentares curtos se une ao conjunto de interesses dos consumidores por uma alimentação mais saudável e pelo saber da origem do produto que estão consumindo (GOODMAN, 2003; MARESCOTTI; BELLETTI, 2012; CASSOL; SCHNEIDER, 2015).

Nesta perspectiva, as novas configurações da cadeia de suprimentos de alimentos constituem um elemento crucial nas estratégias subjacentes a novas práticas, como da agricultura orgânica, da produção de qualidade e da venda direta ao consumidor (COTEUR et al., 2019; HUBEAU et al., 2017).

As cadeias curtas de abastecimento alimentar desempenham papel "transformador" frente aos efeitos sociais, ambientais e culturais negativos das cadeias de abastecimento convencionais e industrializadas. Pois, geralmente os alimentos comercializados nas cadeias curtas são orgânicos, frescos, 
tradicionais e, às vezes, de alta qualidade, que remetem a um conjunto de atributos locais. Por este motivo também permitem, normalmente, a participação de pequenas propriedades agrícolas. Assim, essas cadeias de abastecimento constituem-se uma inovação mais ou menos radical no sistema alimentar global (BELLETTI; MARESCOTTI, 2013; ROSSI, 2012).

No caso brasileiro, a agricultura familiar demonstra efetiva contribuição na produção de alimentos, da mesma forma em que, ajuda a superar a insegurança alimentar. Exemplo disso, são os mercados institucionais, em que ela desempenha papel importante no abastecimento de alimentos para escolas por intermédio do Programa Nacional de Alimentação Escolar (PNAE) e através de compras do governo para grupos de pessoas mais vulneráveis ou pobres por meio do Programa de Aquisição Alimentar (PAA) (SCARABELOT; SCHNEIDER, 2012).

Entre os mercados locais, as feiras ganham destaque por serem uma possibilidade para os produtores rurais se inserirem no mercado e se reproduzirem ao logo do tempo. Passo Fundo, município gaúcho, localizado no norte do estado do Rio Grande do Sul (RS), possui a Feira Municipal dos Produtores Rurais de Passo Fundo/RS. Ela é administrada pela Assembleia Geral, é apoiada pela Prefeitura Municipal de Passo Fundo, através da Secretaria do Interior (SECRINT), EMATER Municipal e Sindicato dos Trabalhadores Rurais de Passo Fundo (STRPF). Esta feira tem como objetivo estimular o pequeno e médio produtor rural a produzir e possibilitar a comercialização de seus produtos diretamente ao consumidor, a preços acessiveis.

Dessa forma, o objetivo deste estudo é analisar os fatores de inserção nos mercados locais, sob a ótica dos feirantes que comercializam na Feira Municipal dos Produtores Rurais de Passo Fundo-RS. 0 artigo está dividido em cinco seções, a começar por esta introdução. A segunda seção trata de uma breve discussão acerca das cadeias curtas de comercialização. Na terceira seção, são apresentados os procedimentos metodológicos. Na quarta seção, a sistematização e análise dos resultados e, por fim, as considerações finais da pesquisa.

\section{A PRODUÇÃO E COMERCIALIZAÇÃO DE ALIMENTOS POR INTERMÉDIO DAS CADEIAS CURTAS DE COMERCIALIZAÇÃO}

As cadeias globais de alimentos, baseados na especialização produtiva, economias de escala, novas tecnologias, ao mesmo tempo, em que tem permitido o acesso ao alimento a custos decrescentes. Por outro, guardada as devidas proporções, gera externalidades negativas em termos econômicos, ambientais, sociais, e ainda, impacta na qualidade nutricional dos alimentos e na saúde (BELLETTI; MARESCOTTI, 2017; SONNINO; MARSDEN, 2006). Assim, relações sociais não são apenas sobre as relações interpessoais de 
confiança, mas também culturais e políticas, as quais geram novos valores comerciais sobre os produtos alimentares comercializados (CHIFFOLEAU, 2009; TRIVETTE, 2017).

Uma das características das cadeias curtas de produção e comercialização está relacionada à distância física de extensão e percurso entre os produtores primários e os destinatários finais dos alimentos (CASSOL; SCHNEIDER, 2015). Desse modo, as cadeias curtas de produção e comercialização tem aproximado diferentes atores nas redes agroalimentares.

Os pioneiros neste assunto das redes agroalimentares alternativas, cadeias curtas de abastecimento alimentar ou, então, Short Food Supply Chains - SFSCs, em nivel mundial, pode-se destacar: Marsden, Banks e Bristow (2000); Hinrichs (2000); Renting, Marsden e Banks (2003); Goodman (2003); Sonnino e Marsden (2006); Rossi e Brunori (2010); Brunori, Rossi e Malandrin (2011); Belletti e Marescotti (2013). No caso Brasileiro, destacam-se os trabalhos realizados por Ferrari (2011); Scarabelot e Schneider (2012); Duarte e Thomé (2015); Schneider e Gazolla (2017); Strate e Conterato (2018).

A abordagem das cadeias agroalimentares curtas remete a formas de comercialização da produção agrícola que aproxima e/ou estreita as relações entre produtores e consumidores, desenvolvendo uma conexão que permite maior interatividade e confiança mútua. Iniciativas de comercialização desse tipo é uma inovação social (ROSSI, 2012) que possibilita aos agricultores se reproduzirem economicamente, permite a aproximação entre agricultores e consumidores e, em uma perspectiva mais ampla, contribui para o desenvolvimento local.

"As escolhas individuais são efetivamente moldadas pelas estruturas sociais e respectivas convenções, pelos modos culturais dominantes, contexto institucional, infraestrutura, teconologias, mercados em que vivem os consumidores" (ROSSI; BRUNORI, 2017, p. 85). Assim, as novas relações sociais que se desenvolvem nessas redes ultrapassam a esfera das transações econômicas, se mostram mais complexas, mas também capazes de promover importantes mudanças nas práticas alimentares dos consumidores e impulsionar o desenvolvimento regional.

Conforme Hinrichs (2000), a confiança e a conexão social caracterizam os mercados agrícolas diretos, o que leva a distinguir os sistemas alimentares locais do "sistema alimentar global". Ao que tange as redes alternativas, estas engendram uma miríade de relações sociais e culturais que estão no interior dos territórios nos quais emergem, onde as transações econômicas ali realizadas estão imersas nesses valores e são influenciadas por eles (CASSOL; SCHNEIDER, 2015).

Sage (2003) e Sonnino e Marsden (2006), destacam a discussão do conceito de "imersão" (embeddeness) social, usada para enfatizar o componente social da ação econômica. Isto é, para ser bemsucedido, o espaço local precisa "enraizar" conjuntos de princípios organizacionais, saberes e naturezas 
peculiares. A imersão seja vertical (política e institucional) e/ou horizontal (social, espacial e cultural) depende de uma incorporação e manipulação no (e do) espaço, envolvendo economia social e natureza.

A partir da análise da "relocalização" definida pelo produto alimentar, pela cadeia de suprimentos, pelos atores envolvidos ou pela concepção e tipo de comercialização dos produtos alimentares, é que as redes emergentes (cadeias curtas) buscam recapturar o espaço rural na transformação na configuração do espaço agroalimentar. Sob uma nova lógica que define a oferta de alimentos através de relações mais integradas (SONNINO; MARSDEN, 2006).

Ainda, as narrativas de lugar e proveniência nas vendas locais de alimentos, se mostra como uma oportunidade financeira para os produtores, a partir do grande entusiasmo que os consumidores têm demostrado, em busca de alimentos de procedência local rastreável, ou seja, que sua origem é reconhecida (CARROLL; FAHY, 2015).

As estratégias alternativas por parte dos defensores da agricultura familiar, reforçou a importância dos mercados locais e, o poder público, por sua vez, tornou-se cada vez mais importante na regulação do setor com o Serviço de Inspeção Municipal (SIM), na promoção de feiras e no acesso a mercados institucionais, sobretudo, a merenda escolar (WILKINSON, 2008).

O debate em torno das cadeias curtas de abastecimento de alimentos (SFSCs) ganhou o mundo a partir de uma tipologia exposta na produção científica de Marsden, Banks e Bristow (2000); Renting, Marsden e Banks (2003). Os autores propõem três formas de inserção nos mercados agroalimentares. Na cadeia "face a face", ocorre a venda direta, ou seja, os consumidores compram produtos diretamente do produtor onde a autenticidade e a confiança são mediadas pela interação pessoal. Na cadeia de "proximidade espacial", o alcance está além da interação direta, envolve intermediários, os produtos são comercializados em outros mercados locais. E na cadeia de "espacialmente estendida", os produtos são vendidos a consumidores fora da região de produção, em nivel nacional ou até mesmo global, com a incorporação de certificação de qualidade como, por exemplo, os selos de Identificação Geográfica. Conforme o exposto no Quadro 1.

\begin{tabular}{|c|c|c|}
\hline Face a face & Proximidade espacial & Espacialmente estendida \\
\hline $\begin{array}{l}1 \text { - Venda na propriedade. } \\
2 \text { - Feiras livres. } \\
3 \text { - Venda à beira da estrada. } \\
4 \text { - Colheita no campo. } \\
5 \text { - Entrega a domicílio. } \\
6 \text { - Venda por meios eletrônicos. }\end{array}$ & $\begin{array}{l}1 \text { - Mercado de grupos de agricultores. } \\
2 \text { - Marcas regionais. } \\
3 \text { - Grupos de consumidores. } \\
4 \text { - Instituições de apoio à agricultura. } \\
5 \text { - Comércios locais. } \\
6 \text { - Vendas para instituições. } \\
7 \text { - Venda para eventos locais e regionais. }\end{array}$ & $\begin{array}{l}1 \text { - Selo de certificação. } \\
2 \text { - Códigos de produção. } \\
3 \text { - Reputação. }\end{array}$ \\
\hline
\end{tabular}

Fonte: Elaboração própria (2019), com base em Marsden, Banks e Bristow (2000) e Renting, Marsden e Banks (2003) 
As SFSCs representam um modelo de política agroalimentar local capaz de enfrentar a seriedade dos desafios impostos pelas tendências demográficas e pelo aumento da demanda global por alimentos e fibras, de maneira compativel com as estratégias de segurança alimentar do planeta juntamente com as estratégias para a proteção da natureza e da biodiversidade no uso da terra. Tornaram-se promovedoras do desenvolvimento regional a partir da diversidade de produtos disponíveis localmente e dos seus benefícios para a ampliação da segurança alimentar a nível local (AL SHAMSI et al., 2018).

Schneider e Gazolla (2017, p. 13), também destacam as principais cadeias curtas como as vendas diretas nas propriedades, feiras locais, lojas de agricultores, mercados dos agricultores/produtores (farmers markets), as vendas de porta em porta (box schemes), a colheita direta pelos consumidores nas unidades produtivas (pick your own), o comércio eletrônico, formas de codivisão dos riscos de produção dos alimentos entre consumidores e produtores, os grupos de consumidores coletivos e as diversas modalidades de associações entre produtores e consumidores.

Portanto, os diferentes tipos de cadeias curtas mostram o quanto é importante a questão da confiança (CASSOL; SCHNEIDER, 2017), para consolidar as formas alternativas contemporâneas de produção e consumo.

\section{PROCEDIMENTOS METODOLÓGICOS}

O ambiente de pesquisa é delimitado à Feira Municipal dos Produtores Rurais de Passo FundoRS, que acontece no município há mais de 40 anos. Neste espaço são comercializados frutas, verduras, legumes, massas, pães, bolachas, carnes e embutidos entre outros produtos advindos das propriedades rurais e agroindústrias.

A população de feirantes constatada no momento da pesquisa à campo, em setembro de 2018, era de 47 participantes ${ }^{1}$. Assim, observa-se uma redução deles em relação ao ano de 2012, em que haviam 66 feirantes (CASSOL, 2013). Como foram entrevistados os 47 feirantes, infere-se que foi realizado um censo. Uma coleta de dados em formato de censo consiste em considerar a população do referido local ou região a ser pesquisado, é uma técnica indicada para populações pequenas (MALHOTRA, 2001; HAIR, JR. et al., 2005).

A partir de um estudo exploratório realizou-se a caracterização dos produtores que atuam na Feira do Produtor de Passo Fundo-RS, bem como foi identificado as suas percepções, principalmente no que

\footnotetext{
${ }^{1}$ Conforme relação disponibilizada pela secretária da associação em junho de 2018. 0 número de feirantes varia de acordo com as assembleias que são realizadas, onde alguns membros podem ser desligados e outros admitidos.
} 
se refere a aspectos mercadológicos. A investigação empírica e a coleta de dados foram realizadas por intermédio da aplicação de um roteiro de pesquisa estruturado, elaborado com base em Cassol (2013) e Conteratto (2017). Foram realizadas 12 incursões a campo, em que consistia a visitação e/ou observação da Feira, assim como, a aplicação do roteiro junto aos produtores feirantes, nos dois dias da semana em que acontecia a Feira: sábados de manhã e quartas-feiras à tarde.

Os dados da caracterização dos produtores que atuam na Feira do Produtor de Passo Fundo-RS foram tabulados e analisados a partir do software Exce/ ${ }^{\circledR}$ 2016. Pela natureza das questões contidas no roteiro, foi realizada análises a partir da estatística descritiva. Para efeitos de análise os feirantes foram estratificados em três grupos.

O primeiro denominou-se de produtores/comercializadores de produtos "in natura" e é composto por 24 agricultores que produzem e comercializam majoritariamente hortaliças, legumes e frutas; o segundo grupo de agricultores/comercializadores de produtos "agroindustrializados", em que a fonte de renda advém majoritariamente de produtos transformados por meio de agroindústrias familiares, composto por 15 agricultores; e, o terceiro grupo de "comercializadores intermediários", configurado por indivíduos que não produzem, mas que comercializam produtos adquiridos de outros agricultores e fornecedores, composto por sete feirantes. Um feirante foi excluído da análise global, uma vez que pode ser considerado um "outliers", ou seja, sua atividade é de natureza muito específica (produção e comércio de artesanato). Assim, a análise refere-se a aspectos relacionados a 46 feirantes.

\section{A INSERÇÃO DOS PRODUTORES RURAIS FAMILIARES AOS MERCADOS ALIMENTARES LOCAIS}

\subsection{CARACTERIZAÇÃO DOS FEIRANTES QUE COMERCIALIZAM NA FEIRA DO PRODUTOR RURAL DE PASSO FUNDO-RS}

Aspectos relacionados às características dos agricultores (escolaridade, o acesso e a leitura adequada das informações), as formas de gestão, a perspectiva de sucessão influem, em maior ou menor grau, e contribuem para moldar as percepções, bem como, nas decisões estratégicas dos agricultores (BROWN; DAIGNEAULT; DAWSON, 2019; WRIGHT; BROWN, 2018).

A idade dos produtores que atuam na Feira (Quadro 2), em larga medida, vão ao encontro a uma problemática já identificada por outros autores (SPANEVELLO et al., 2017; MAIA; BUAINAIN, 2015; BALSADI; DELGROSSI, 2018), como as migrações rurais e envelhecimento da população rural. Assim, em uma perspectiva de longo prazo, a manutenção dessa configuração pode significar um impasse no 


\section{Gestãoe \\ Desenvolvimento}

e-ISSN: 2446-6875

p-ISSN: 1807-5436

fornecimento de alimentos em espaços como feiras, por exemplo. No que se refere ao sexo dos feirantes, do total $54,30 \%$ são do sexo masculino e $45,70 \%$ do sexo feminino. Considerando a estratificação dos feirantes (agricultores/comercializadores in natura; agricultores/comercializadores de agroindustrializados e comercializadores intermediários), a diferença mais expressiva está nos intermediários, uma vez que $85,70 \%$ são do sexo masculino.

O nível de escolaridade (Quadro 2) é representado majoritariamente por indivíduos que possuem ensino médio completo (48,94\%), ao considerar os que possuem ensino técnico $(4,26 \%)$; superior incompleto $(10,64 \%)$ e completo $(8,41 \%)$ e, aqueles que possuem ensino fundamental incompleto $(12,77 \%)$.

Em termos de tamanho da família, predominam aquelas constituídas de três membros e cinco membros, respectivamente (Quadro 2). Em 44,68\% das famílias todos os seus integrantes estão ligados as atividades de produção e/ou comercialização na feira. Nas demais (55,32\%), nem todos os membros que constituem a família trabalham em função da feira, ou seja, exercem outras atividades e/ou profissão. Portanto, entende-se como uma forte característica da agricultura familiar, a capacidade de estabelecer conexões que possibilitam a realização de atividades agrícolas e não agrícolas na propriedade ou fora da mesma, gerando receitas que mantém a família no meio rural, bem como a diversidade produtiva presente tanto nas atividades realizadas, como na produção alimentar (PERONDI; RIBEIRO, 2000; WILKINSON, 2008). 


\begin{tabular}{|c|c|c|}
\hline \multirow{4}{*}{ 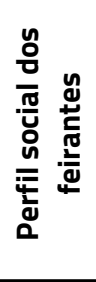 } & Idade & $\begin{array}{l}\text { Predomina indivíduos com mais de } 30 \text { anos }(72,34 \%) \text {, baixa concentração de indivíduos } \\
\text { considerados jovens pela FAO. }\end{array}$ \\
\hline & Sexo & Feminino $(45,70 \%)$; Masculino $(54,30 \%)$ \\
\hline & Escolaridade & Predomina indivíduos com ensino médio completo $(48,94 \%)$. \\
\hline & Tamanho da família & Predominam famílias de 3 pessoas $(21,28 \%)$; 4 pessoas $(31,91 \%) ; 5$ pessoas $(21,28 \%)$. \\
\hline \multirow{4}{*}{ 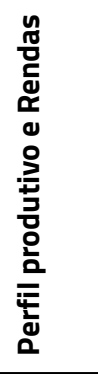 } & Área Total & Predomina UPAs de 0,6 a 10 ha $(55,32 \%)$. \\
\hline & Origem dos produtos & $\begin{array}{l}\text { Predomina produção própria do que comercializam na feira }(70,21 \%) \text {; alguns de seus } \\
\text { produtos são produzidos por outras pessoas }(14,89 \%) \text { i intermediários }(14,89 \%) \text {. }\end{array}$ \\
\hline & Diversificação & $\begin{array}{l}\text { Somente atividades de feira }(51,06 \%) \text {; possuem outra atividade agrícola além da feira } \\
(48,94 \%) \text {. }\end{array}$ \\
\hline & Renda Bruta mensal & $\begin{array}{l}\text { Concentração de famílias que obtém uma renda bruta total mensal de } \mathrm{R} \$ 3.501,00 \text { a } \mathrm{R} \$ \\
5.000,00(40,43 \%) \text {; entre } \mathrm{R} \$ 1.601,00 \text { a } \mathrm{R} \$ 2.000,00(14,89 \%) \text {. }\end{array}$ \\
\hline \multirow{3}{*}{ 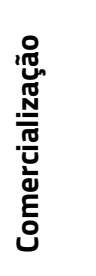 } & Tempo de feira & Até 10 anos $(36,17 \%)$; entre 11 e 25 anos (48,94\%); acima de 25 anos $(14,90 \%)$. \\
\hline & $\begin{array}{l}\text { Principais produtos } \\
\text { comercializados }\end{array}$ & $\begin{array}{l}\text { Verduras, frutas, legumes, grãos, flores, mudas de temperos/chás e artesanato. 23,40\% } \\
\text { dos produtores possuem agroindústria de panificados, lácteos, mel. }\end{array}$ \\
\hline & $\begin{array}{l}\text { Frequência de } \\
\text { comercialização }\end{array}$ & $\begin{array}{l}\text { Quartas-feiras e sábados }(59,57 \%) \text {; três dias em que ocorre a feira }(29,79 \%) \text {; somente nos } \\
\text { sábados de manhã }(10,64 \%) \text {. }\end{array}$ \\
\hline
\end{tabular}

Fonte: Dados da pesquisa a campo (2018)

Quanto a área total das propriedades rurais dos produtores feirantes, 29,79\% possuem de 0,6 hectares a 5 hectares, 14,89\% e 10,64\% área de 5,01 hectares a 10 hectares, o mesmo percentual também representa os feirantes que não possuem propriedade rural. E 4,26\% não sabiam ou não responderam. Com exceção dos que não possuem propriedade rural (10,64\%), os demais se caracterizam como pequenos produtores rurais (Quadro 2).

Entre os que possuem propriedade rural, $51,06 \%$ dos feirantes não possuem outra atividade agrícola, além daquelas que comercializam na feira. Já, os outros 48,94\% possuem outra atividade, em que se destacam a produção de grãos na maioria delas, produção de leite, suinocultura, avicultura e criação de ovinos (Quadro 2). Tal configuração dos produtores vai ao encontro de uma discussão realizada por Wilkinson (2008), em que o autor menciona que as funções e/ou da pequena produção são diversas, como a produção para autoconsumo, comercialização de produtos tracionais, produção de grãos para alimentação do sistema de criação e venda, bem como a produção agroindustrial. Em uma perspectiva mais ampla, esses componentes estão, em maior ou menor grau presentes nas Unidades de Produção Agrícola (UPAs) dos feirantes. 
Em relação à renda mensal (Quadro 2), observa-se uma concentração de famílias (40,43\%) que obtém uma renda bruta total de $\mathrm{R} \$ 3.501,00$ a $\mathrm{R} \$ 5.000,00$. Os feirantes afirmam que a renda auferida na feira varia muito de cada dia, por exemplo, nos sábados, geralmente, é o dia em que mais vendem, por ter maior movimentação de pessoas.

Entre os produtores feirantes $70,21 \%$ afirmam que eles próprios produzem todos os produtos em que comercializam na feira e 14,89\% afirmam que alguns de seus produtos são produzidos por outras pessoas como vizinhos, parentes/amigos, em que os produtos são chás, vinhos, erva, ovos, frutas, flores de corte e animais para abate (Quadro 2).

O mesmo percentual de $14,89 \%$ representa os feirantes que compram todos os produtos, apenas revendem na feira (Quadro 2). Neste caso, não são produtores rurais, mas atuam como pequenos comerciantes (atravessadores), considerados também como fruteiros, que tiveram sua participação assegurada para venda no espaço da feira, pelo argumento de aumentar a gama de oferta de alimentos, especialmente de frutas, não produzidas na região. No entanto, também comercializam produtos locais e tradicionais da região oriundos da agricultura familiar. Apesar de atuarem de forma distinta dos produtores feirantes, os atravessadores não são distinguidos no ambiente da feira.

Os principais produtos comercializados pela maioria dos feirantes são verduras, frutas, legumes e grãos. Outra parcela, $23,40 \%$ dos produtores, possuem agroindústria de panificados, bolachas, lácteos e mel. Junior e Trentin (2006) veem a agroindústria familiar como uma importante ferramenta para a geração de renda no meio rural, pois, contribui para um desenvolvimento sustentável dos atores sociais. Além de, encaixar-se perfeitamente em inúmeras realidades, que colabora para os territórios de forma multidimensional e diversificada. Ademais, promove a recuperação e preservação dos hábitos culturais e do meio ambiente, em que os investimentos iniciais são baixos e os produtos finais podem ser remetidos para o comércio local. Dessa forma, as agroindústrias tem papel importante fortalecendo e incentivando os agricultores familiares locais.

\subsection{A FEIRA DO PRODUTOR DE PASSO FUNDO/RS: EVOLUÇÃO E VISÃO DOS FEIRANTES SOBRE O ATUAL ESPAÇO}

As feiras livres de venda direta é um dos tipos mais tradicionais de inserção nos mercados por intermédio de cadeias curtas de comercialização, as relações entre os atores acontecem diretamente por meio de interações face a face. Esse tipo de comercialização é um exemplo de valores sociais e culturais, além do mercantil, que circulam dentro desses ambientes (RENTING; MARSDEN; BANKS, 2003; CASSOL; SCHNEIDER, 2017). 
A Feira do Produtor de Passo Fundo, localizada no município de Passo Fundo é um espaço promissor de estudos e pesquisas. Por intermédio da literatura, identificou-se além de Cassol (2013), o estudo de Rocha et al. (2010) e Rocha, Costa e Castoldi (2012). Esta última, identificou que as hortaliças e as frutas são os produtos mais comercializados e, dentre os problemas existentes na Feira os feirantes e consumidores destacaram os aspectos higiênicos e sanitários como os mais importantes.

A Feira do Pequeno Produtor existe no município de Passo Fundo desde 1975, a partir da iniciativa de 12 pequenos agricultores. Inicialmente ela acontecia ao ar livre na Praça General Neto, mais adiante passou a ser realizada na Praça Tamandaré (CASSOL, 2013). Em 1984 foi deslocada para o Parque da Gare, na antiga Estação Férrea do município, e ficou instalada neste local até início de 2016.

Até então o espaço da feira era gerido pela Prefeitura Municipal, que cobrava uma taxa dos agricultores para uso do local. Já em 1996, foi criada a Associação da Feira Municipal dos Produtores Rurais de Passo Fundo que passou a gerir e organizar o seu funcionamento. Trata-se de uma associação civil, sem fins lucrativos ou econômicos, com duração de prazo indeterminado, de caráter representativo e reivindicatório (ESTATUTO DA ASSOCIAÇÃO DA FEIRA DOS PRODUTORES RURAIS DE PASSO FUNDO, 1996).

Atualmente, a feira ainda ocorre no Parque da Gare, no entanto, recebeu um novo pavilhão, em frente ao espaço antigo, construído pela Prefeitura Municipal, especialmente para os produtores comercializarem seus produtos. Inaugurado no ano de 2016, o novo espaço é moderno e adequado às necessidades do comércio, possui uma estrutura de 1.100 metros quadrados, atende as normas sanitárias e de acessibilidade, com acesso por rampas e escadas. As bancas são individualizadas por família e divididas em setores de produtos específicos.

Vale destacar o papel desempenhado pela rede de instituições para a construção do mercado da feira, juntamente com os demais atores envolvidos, com o propósito de proporcionar aos habitantes do município acesso aos alimentos locais e de qualidade. Além, da aproximação física e simbólica estreitando as relações entre meio rural e urbano. Na Figura 1, é ilustrado as relações de funcionamento da feira através dos atores sociais (produtores, consumidores) e institucionais como: EMATER Municipal, Sindicato dos Trabalhadores Rurais de Passo Fundo (STRPF), Secretaria do Interior (SECRINT) e Vigilância Sanitária (VS). 


\section{Gestãoe \\ Desenvolvimento}

e-ISSN: 2446-6875

p-ISSN: $1807-5436$

\section{Figura 1 - Relações dos atores envolvidos no funcionamento da Feira do Produtor de Passo Fundo/RS}

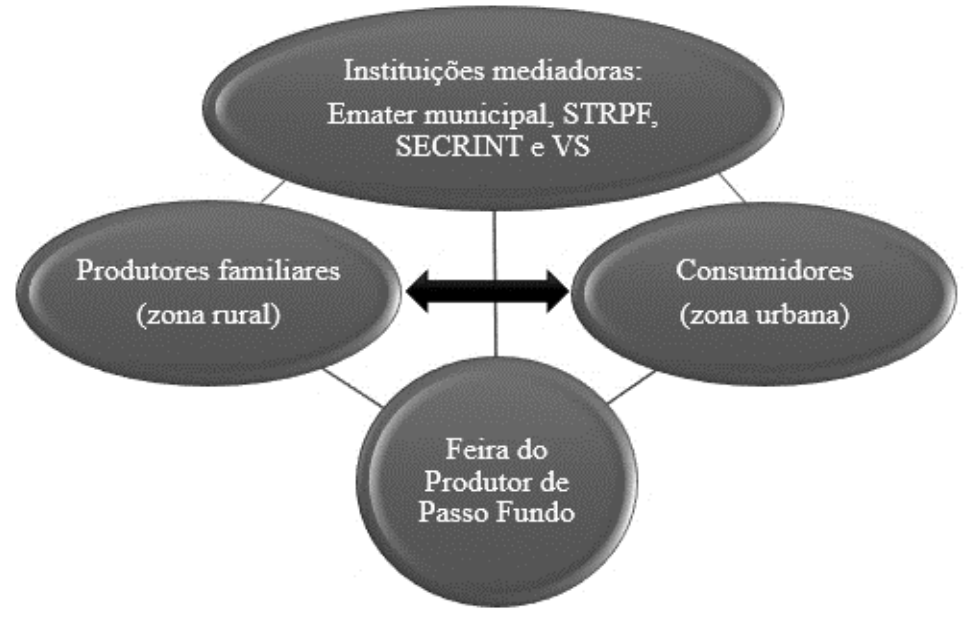

Fonte: Elaboração própria (2019). Ver também Cassol (2013, p. 120)

No que se refere à percepção dos feirantes (maio-setembro de 2018), referente ao espaço novo (pavilhão) da feira, a partir dos escores da Tabela 1, percebe-se uma avaliação positiva, sobretudo, ao que se refere às instalações relacionadas a espaços mais amplos e comodidade dos consumidores. É importante frisar aspectos relacionados à adequação às normas sanitárias e acessibilidade, dois aspectos relevantes na atualidade. A primeira, diz respeito a uma problemática de difícil adequação, considerada um dos principais entraves nesse tipo de espaço de comercialização, e uma das maiores preocupações dos consumidores. É interessante salientar que esses fatores (condições de higiene e limpeza) foram mencionados no estudo de Rocha, Costa e Castoldi (2012), em pesquisa realizada no espaço antigo da referida feira, como limitantes no ambiente de negócios. Assim, o novo espaço atende as normas sanitárias e melhorou muito condições de funcionamento da feira. A segunda, é uma questão social que amplia o acesso às pessoas que tem limitações, sobretudo, físicas de usufruir espaços coletivos.

Entre os escores mais baixos, ou seja, em que os feirantes avaliam que não houve um melhor desempenho em relação ao espaço antigo é o estacionamento próprio da feira. Por um problema estrutural na construção, os feirantes mencionam que eles próprios não têm um espaço próximo do pavilhão para carga e descarga dos produtos, que resulta em transportar os produtos, muitas vezes, de estacionamentos distantes.

O pior escore em relação a estrutura de depósito, se explica pelo fato de os feirantes não possuírem depósito dentro da feira, apenas dispõem do espaço da banca em que comercializam. Também é algo que os feirantes dispensam a necessidade, pois a maior parcela dos produtos comercializados é perecível ou 


\section{Gestãoe \\ Desenvolvimento}

e-ISSN: 2446-6875

p-ISSN: $1807-5436$

tem um ciclo de vida menor, então já organizam um volume de produtos que, geralmente, é todo vendido no mesmo dia.

Tabela 1 - Percepção dos produtores quanto ao espaço novo da Feira do Produtor de Passo Fundo-RS

\begin{tabular}{lcccc}
\hline \multicolumn{1}{c}{ Variáveis } & Mínimo & Máximo & Média & Desvio Padrão \\
\hline Ambiente agradável para os consumidores & 2 & 5 & 4,77 & 0,677 \\
Atender as normas sanitárias & 1 & 5 & 4,68 & 1,052 \\
Espaço amplo & 1 & 5 & 4,66 & 0,888 \\
Desenvolvimento local municipal & 1 & 5 & 4,57 & 0,950 \\
Instalações adequadas & 1 & 5 & 4,20 & 1,440 \\
Incentivo para os feirantes continuarem nas atividades & 1 & 5 & 4,09 & 1,522 \\
Diversificou as variedades de produtos ofertados & 1 & 5 & 3,77 & 1,660 \\
Acessibilidade & 1 & 5 & 3,61 & 1,755 \\
Aumentar a qualidade e a gama de produtos & 1 & 5 & 3,48 & 1,532 \\
Aumentar o rendimento familiar dos feirantes & 1 & 5 & 3,30 & 1,579 \\
Aumento no número de feirantes & 1 & 5 & 3,11 & 1,617 \\
Aumento no número de consumidores & 1 & 5 & 2,77 & 1,655 \\
Modificou sua forma de produzir depois que adentrou a feira & 1 & 5 & 2,66 & 1,842 \\
Aumentar as vendas em relação ao espaço antigo & 1 & 5 & 5 & 2,66 \\
Estacionamento próprio para a feira & 1,725 \\
Estrutura de Depósitos & 1 & 3 & 1,34 & 0,745 \\
\hline
\end{tabular}

Fonte: Dados da pesquisa a campo (2018)

De modo geral, observa-se uma disparidade entre os produtores feirantes quanto sua percepção do novo ambiente de comercialização, em que uns estão satisfeitos enquanto que outros apontam insatisfação. A variável que se refere a ter modificado a forma de produzir depois que adentrou a feira, apresenta maior desvio padrão, ou seja, teve maior dispersão no escore dos respondentes.

\subsection{PERCEPÇÃO DOS AGRICULTORES SOBRE O AMBIENTE MERCADOLÓGICO NA FEIRA DO PRODUTOR DE PASSO FUNDO-RS}

\subsubsection{As relações produtor-consumidor construídas no espaço da feira}

As cadeias agroalimentares curtas podem ser entendidas como a pretensão de atores em determinado ambiente, de construir novos mercados com formas alternativas de interação entre a 
produção e o consumo (SCHNEIDER; GAZOLLA, 2017). Neste contexto, a partir da teoria das convenções (WILKINSON, 2008; ROSSI; BRUNORI, 2017), chamam atenção para as relações sociais e a ideia de que os mercados agroalimentares podem ser "socialmente construídos".

Quando inquiridos sobre os aspectos que, na sua condição de produtor/comercializador mais valorizam, em relação a valorização dos produtores na sua relação com os consumidores (Tabela 2), destacam-se aspectos como: a satisfação pessoal de atuar na feira; o respeito; e, a amizade. Nota-se o maior desvio padrão, que denota maior dispersão no escore dos respondentes intermediários, quanto a confiança e ao tempo de atuação na feira.

Durante as entrevistas, muitos produtores feirantes mencionaram fortes relações de confiança e amizade em que criam com os consumidores. Isto vai ao encontro da discussão de (HINRICHS, 2000; CHIFFOLEAU, 2009; CASSOL; SCHNEIDER, 2015; TRIVETTE, 2017) quanto as relações sociais entre produtor-consumidor, que desencadeia a capacidade de estabelecer relações confiáveis e positivas, sobretudo, o reconhecimento da importância do trabalho de todas as partes envolvidas. Que remete também às relações culturais e políticas.

Tabela 2 - Valorização do produtor na relação com os consumidores da Feira do Produtor de Passo Fundo-RS

\begin{tabular}{|c|c|c|c|c|c|c|}
\hline \multirow[b]{2}{*}{ Variáveis } & \multicolumn{2}{|c|}{$\begin{array}{c}\text { Produtor/comercializador "in } \\
\text { natura" }\end{array}$} & \multicolumn{2}{|c|}{$\begin{array}{l}\text { Produtor/comercializador } \\
\text { "agroindustrializados" }\end{array}$} & \multicolumn{2}{|c|}{$\begin{array}{l}\text { Comercializador } \\
\text { Intermediários }\end{array}$} \\
\hline & Média & Desvio Padrão & Média & Desvio Padrão & Média & Desvio Padrão \\
\hline Amizade & 4,96 & 0,204 & 4,87 & 0,516 & 4,71 & 0,756 \\
\hline Respeito & 4,96 & 0,204 & 4,93 & 0,258 & 5,00 & 0,000 \\
\hline Confiança & 4,92 & 0,282 & 5,00 & 0,000 & 4,43 & 1,512 \\
\hline $\begin{array}{l}\text { Satisfação no } \\
\text { fornecimento de } \\
\text { alimentos }\end{array}$ & 5,00 & 0,000 & 5,00 & 0,000 & 4,86 & 0,378 \\
\hline $\begin{array}{l}\text { O tempo de atuação na } \\
\text { feira }\end{array}$ & 4,92 & 0,282 & 4,87 & 0,352 & 4,43 & 1,134 \\
\hline $\begin{array}{l}\text { História, tradição e } \\
\text { valores }\end{array}$ & 4,92 & 0,408 & 4,67 & 0,900 & 5,00 & 0,000 \\
\hline
\end{tabular}

Fonte: Dados da pesquisa a campo (2018)

Em uma perspectiva estratificada de agricultores, por tipo de produto comercializado (Tabela 3), entendem-se aspectos como a questão de rotulagem, informações nutricionais e embalagens, se sobressaia entre os produtores/comercializadores de produtos agroindustrializados. Esse comportamento pode ser explicado pela condição do próprio produto, uma vez que, ele é fruto da agregação e manipulação 


\section{Gestãoe \\ Desenvolvimento}

e-ISSN: 2446-6875

p-ISSN: $1807-5436$

de diferentes ingredientes e processos. Pela demanda dos consumidores, sobretudo, frente à valorização de fatores referente à segurança dos alimentos, principalmente, naqueles de origem animal; e da própria legislação que prevê condições diferenciadas para produtos comercializados "in natura", assim como para produtos de origem animal e vegetal; e também para produtos agroindustrializados.

Em uma perspectiva mais ampla, os feirantes acreditam que os consumidores também valorizem aspectos subjetivos, atributos de qualidade relacionados às relações de confiança, de saber a origem e as formas de produção (Tabela 3). Em detrimento, por exemplo, de fatores obrigatórios para a comercialização de produtos típicos de cadeias longas, em que não se tem informações mais objetivas de quem são e como são produzidos esses alimentos. Essas configurações vão ao encontro do exposto por RucabadoPalomar e Cuéllar Padilla (2018), a partir de estudo realizado no Sul da Espanha. De acordo com os autores, os alimentos chegam ao consumidor incorporados com a informação sobre o alimento, os métodos de produção utilizados e as pessoas envolvidas no processo; assim, estes também são resultados da localidade ou mesmo da propriedade onde são produzidos. 


\section{Gestãoe \\ Desenvolvimento}

e-ISSN: 2446-6875

p-ISSN: 1807-5436

Tabela 3 - Visão dos produtores sobre o que os consumidores valorizam quando compram os produtos em sua banca na

Feira do Produtor de Passo Fundo-RS

\begin{tabular}{|c|c|c|c|c|c|c|}
\hline \multirow[b]{2}{*}{ Variáveis } & \multicolumn{2}{|c|}{$\begin{array}{l}\text { Produtor/comercializador } \\
\text { "in natura" }\end{array}$} & \multicolumn{2}{|c|}{$\begin{array}{l}\text { Produtor/comercializador } \\
\text { "agroindustrializados" }\end{array}$} & \multicolumn{2}{|c|}{ Intermediários } \\
\hline & Média & Desvio Padrão & Média & Desvio Padrão & Média & Desvio Padrão \\
\hline $\begin{array}{l}\text { Conhecimento do "modo } \\
\text { de fazer" utilizado na sua } \\
\text { produção }\end{array}$ & 4,63 & 0,924 & 4,93 & 0,258 & 4,86 & 0,378 \\
\hline $\begin{array}{l}\text { Saber a origem dos } \\
\text { produtos }\end{array}$ & 4,67 & 0,917 & 4,93 & 0,258 & 4,86 & 0,378 \\
\hline $\begin{array}{l}\text { Conhecimento da } \\
\text { Qualidade dos produtos }\end{array}$ & 4,71 & 0,908 & 4,93 & 0,258 & 5,00 & 0,000 \\
\hline $\begin{array}{l}\text { Cuidados com a aparência } \\
\text { dos produtos }\end{array}$ & 5,00 & 0,000 & 4,93 & 0,258 & 5,00 & 0,000 \\
\hline $\begin{array}{l}\text { Relação de confiança nos } \\
\text { produtos }\end{array}$ & 4,88 & 0,448 & 4,93 & 0,258 & 4,86 & 0,378 \\
\hline Amizade & 4,79 & 0,588 & 4,87 & 0,352 & 5,00 & 0,000 \\
\hline Respeito & 4,79 & 0,588 & 4,87 & 0,352 & 5,00 & 0,000 \\
\hline Venda face a face & 4,92 & 0,282 & 4,87 & 0,352 & 5,00 & 0,000 \\
\hline $\begin{array}{l}\text { Comercializar sempre ou } \\
\text { quase sempre do mesmo } \\
\text { produtor }\end{array}$ & 4,92 & 0,408 & 4,93 & 0,258 & 5,00 & 0,000 \\
\hline Operar de forma legalizada & 4,17 & 1,167 & 3,60 & 1,595 & 2,86 & 1,464 \\
\hline Possuir selo de qualidade & 2,71 & 1,233 & 3,20 & 1,568 & 2,57 & 1,618 \\
\hline Estarem embalados & 3,25 & 1,391 & 3,80 & 1,373 & 2,57 & 1,397 \\
\hline $\begin{array}{l}\text { Possuir rótulo com valores } \\
\text { nutricionais }\end{array}$ & 3,00 & 0,590 & 3,20 & 1,781 & 2,71 & 0,756 \\
\hline $\begin{array}{l}\text { Preços diferenciados dos } \\
\text { concorrentes }\end{array}$ & 4,46 & 1,103 & 4,20 & 1,146 & 4,43 & 1,512 \\
\hline
\end{tabular}

Fonte: Dados da pesquisa a campo (2018)

Quanto a variável comercializar sempre ou quase sempre do mesmo produtor, destaca-se que 97,87\% afirmam ter consumidores que sempre compram os seus produtos, os fiéis de "carteirinha", mas têm também a clientela variada e os que vem até a banca por indicação de outras pessoas que já compraram. Observa-se os maiores desvios padrão para os agroindustrializados, ao que se refere em 
possuir rótulo com valores nutricionais e para os intermediários, quanto a questão de possuir selo de qualidade, que influiu maior dispersão no seus escores de respostas (Tabela 3).

\subsubsection{As razões em participar da feira e de outras redes agroalimentares locais}

De acordo com a Tabela 4, as principais razões pelas quais os produtores começaram a participar e valorizar a Feira foram possibilitar ter uma maior autonomia para comercializar; ser dono do próprio negócio; e não depender dos intermediários, evidenciado nos grupos dos produtores/comercializadores in natura e agroindustrializados. Esses resultados corroboram com as principais características das cadeias curtas de comercialização face a face por meio, especialmente, de vendas em feiras livres, um dos canais mais tradicionais (MARSDEN; BANKS; BRISTOW, 2000; RENTING; MARSDEN; BANKS, 2003; CASSOL; SCHNEIDER, 2017). Além, desta configuração estar relacionada com o fato de a feira ser a principal atividade que gera renda em grande parte dos entrevistados; como Passo Fundo é uma cidade relativamente populosa, em termos de Rio Grande do Sul, não existe falta de demanda por produtos desse tipo.

Os escores baixos (Tabela 4) estão na variável em que se considera a feira como um espaço de comércio da produção do excedente e a possibilidade de cobrar preços maiores. A primeira, se explica pelo fato de os produtores não possuírem excedentes, pois, tudo que produzem, geralmente, já é específico para ser comercializado na feira. A segunda questão, em termos de preços, primeiro, existe um acordo entre os feirantes que estabelece um preço máximo dos produtos; a segunda, é que os preços praticados tendem a ser semelhantes ou inferior ao praticado nos mercados convencionais.

Tabela 4 - Principais razões pelas quais os produtores começaram a participar e valorizar a Feira do Produtor de Passo Fundo-RS

\begin{tabular}{|c|c|c|c|c|c|c|}
\hline \multirow[b]{2}{*}{ Variáveis } & \multicolumn{2}{|c|}{$\begin{array}{l}\text { Produtor/comercializador } \\
\text { "in natura" }\end{array}$} & \multicolumn{2}{|c|}{$\begin{array}{l}\text { Produtor/comercializador } \\
\text { "agroindustrializados" }\end{array}$} & \multicolumn{2}{|c|}{ Intermediários } \\
\hline & Média & Desvio Padrão & Média & Desvio Padrão & Média & Desvio Padrão \\
\hline $\begin{array}{l}\text { Canal de comercialização } \\
\text { para renda da família }\end{array}$ & 4,88 & 0,448 & 4,87 & 0,516 & 5,00 & 0,000 \\
\hline O lucro que ela proporciona & 4,54 & 0,977 & 4,40 & 1,298 & 4,57 & 1,134 \\
\hline O espaço de comércio & 4,88 & 0,612 & 4,73 & 1,033 & 5,00 & 0,000 \\
\hline Agregar valor aos produtos & 4,25 & 1,225 & 4,20 & 1,320 & 3,86 & 1,676 \\
\hline $\begin{array}{l}\text { As relações com os } \\
\text { consumidores }\end{array}$ & 4,54 & 1,141 & 4,93 & 0,258 & 4,86 & 0,378 \\
\hline
\end{tabular}




\section{Gestãoe \\ Desenvolvimento}

e-ISSN: 2446-6875

p-ISSN: $1807-5436$

\begin{tabular}{|c|c|c|c|c|c|c|}
\hline $\begin{array}{l}\text { Não depender dos } \\
\text { intermediários }\end{array}$ & 5,00 & 0,000 & 4,93 & 0,258 & 4,57 & 1,134 \\
\hline Autonomia para vender & 5,00 & 0,000 & 4,93 & 0,258 & 5,00 & 0,000 \\
\hline Ser dono próprio negócio & 5,00 & 0,000 & 4,93 & 0,258 & 5,00 & 0,000 \\
\hline $\begin{array}{l}\text { Canal de comercialização } \\
\text { para o excedente }\end{array}$ & 1,29 & 0,806 & 1,53 & 1,187 & 1,29 & 0,756 \\
\hline $\begin{array}{l}\text { A possibilidade de cobrar } \\
\text { maiores preços }\end{array}$ & 2,50 & 1,745 & 2,93 & 1,792 & 2,43 & 1,618 \\
\hline
\end{tabular}

Fonte: Dados da pesquisa a campo (2018)

Apesar dos preços mais baixos, é possível os produtores terem uma maior margem de lucro através da cadeia curta de comercialização, visto que está dispensa a figura de intermediários, ou seja, é comercializado direto com o consumidor (RENTING; MARSDEN; BANKS, 2003; CASSOL; SCHNEIDER, 2015). Os escores com maior dispersão nas respostas da amostra são observados, justamente na variável da possibilidade de cobrar preços maiores, para o grupo dos produtores in nautra e dos agroindustrializados (Tabela 4).

De um modo geral, no que se refere aos canais de comercialização, em relação à comercialização dos produtos em outros locais além da feira 46,81\% não comercializam em outros locais. Já, 53,19\% comercializam em outros locais como: restaurantes, mercados, fruteiras, açougues, padarias/lanchonetes, vizinhos/conhecidos, floriculturas/decoradores, PNAE e feiras itinerantes.

A parcela que é comercializada fora da feira varia de feirante para feirante, alguns comercializam uma percentagem maior fora da feira, representado por $40 \%$ dos $53,19 \%$, enquanto que outros a maior percentagem da produção é vendida na feira, representado por $60 \%$ dos $53,19 \%$. Entre os motivos que vendem para outros locais além da feira, são: agregar mais renda, vender toda a produção, por falta de clientes suficientes na feira e para vender toda a produção, estratégia de venda, divulgar o nome da agroindústria, venda em locais de conhecidos/amigos, muita concorrência na feira entre os produtos hortifrúti, venda por encomenda e para liquidar o que sobra da feira.

De maneira estratificada, entre o grupo dos produtores de produtos in natura, 58,33\% comercializam em mais de um canal e 41,67\% somente na feira. No grupo dos agroindustrializados, 46,67\% comercializam para outros canais além da feira e 53,33\% somente na feira. Por fim, o grupo de intermediários 57,14\% comercializam seus produtos para outros canais além da feira e $42,86 \%$ que comercializam somente na feira.

Em todos os casos, os produtores estão engajados no mercado local por meio de vendas na feira e em mercados locais dentro do município, num raio geográfico de 10 a 20 km, que corresponde à distância 
das propriedades até a feira e aos outros canais em que comercializam na cidade. No caso de duas agroindústrias que também participam de feiras itinerantes o raio geográfico se estende até cerca de 80 $\mathrm{km}$.

Dentre os argumentos dos feirantes em relação à satisfação em atuar na feira, destacam-se: satisfação em atuar nesta atividade; sobreviver exclusivamente da feira, os produtos são saudáveis, pois, utilizam fertilizantes biológicos na produção das verduras e legumes, tem satisfação em vender na feira; por ser um acréscimo na renda, tem satisfação "a feira é uma terapia"; está dentro de uma cadeia de comercialização em que compras dos produtores proporcionam renda a eles, revende produtos de qualidade, a feira é um passa tempo, trabalho "desestressa-te".

Em geral, nota-se a satisfação dos feirantes em comercializar produtos agroalimentares na feira, evidencia-se as relações econômicas e sociais. Muitas famílias possuem área pequena de terra, o que inviabiliza a realização de outras atividades agrícolas, portanto, sobrevivem exclusivamente da renda obtida com a comercialização na feira.

\section{CONSIDERAÇÕES FINAIS}

O objetivo do presente estudo foi analisar os fatores de inserção nos mercados locais, sob a ótica dos feirantes que comercializam na Feira Municipal dos Produtores Rurais de Passo Fundo-RS. Os dados analisados permitiram considerar a feira como uma rede agroalimentar alternativa, assim como identificou Cassol (2013), e caracterizada como uma cadeia curta de comercialização dada a relação direta de produtor-consumidor, em que se identificaram as tipologias face a face e de proximidade espacial.

A primeira, identificada pela venda direta dos alimentos na feira, e a segunda, pela venda em fruteiras, restaurantes e mercados locais. Além das relações sociais estabelecidas entre os agentes, o resgate da produção local e tradicional é baseada em processos de construção de qualidade e em produtos mais saudáveis, o que difere do sistema agroalimentar consolidado.

Em geral, a produção e comercialização é realizada pelos membros da família que, em sua grande maioria, comercializam verduras, frutas, legumes, massas, bolachas, entre outros diversos produtos coloniais e artesanais, além de flores. 0 canal da feira permite o acesso dos consumidores a produtos frescos e com características sociais e culturais próprias do município. Cria-se uma (re)aproximação entre a zona rural (produtores) e zona urbana (consumidores).

Os resultados corroboram a literatura sobre a relevância de relações econômicas, sobretudo sociais, construídas no âmbito das cadeias agroalimentares curtas, como rastreabilidade informal, confiança, qualidade e origem dos alimentos. A maioria dos produtores feirantes mostraram sua plena satisfação 


\section{Gestãoe \\ Desenvolvimento}

e-ISSN: 2446-6875

p-ISSN: $1807-5436$

em produzir e comercializar seus produtos, inclusive criar vínculos de amizade e confiança com os consumidores. É evidente que a feira permite a reprodução socioeconômica dessas famílias de pequenos agricultores em que, muitas vezes, a atividade é repassada de geração em geração.

Para estudos futuros, sugere-se ter a contrapartida da pesquisa, sob a óptica dos consumidores, em relação a sua percepção quanto ao novo espaço da Feira e quanto às relações produtor-consumidor construídas no espaço da feira, assim como investigar as motivações de consumo neste local. 0 estudo não apresentou limitações.

\section{REFERÊNCIAS}

AL SHAMSI, K. B. et al. A sustainable organic production model for "food sovereignty" in the United Arab Emirates and Sicily-Italy. Sustainability, v. 10(3), 620, 2018.

BALSADI, O. V.; DELGROSSI, M. D. Labor and Employment in Brazilian Northeastern Agriculture: a look at the 2004-2014 period. Revista de Economia e Sociologia Rural, v. 56, n. 1, p. 19-34, 2018.

BELLETTI, G.; MARESCOTTI, A. Potenzialità e limiti delle iniziative di filiera corta. Progress in Nutrition, v. 15, n. 3, p. 146-162, 2013.

BELLETTI, G.; MARESCOTTI, A. Inovações econômicas em cadeias curtas de abastecimento alimentar. In: SCHNEIDER, S.; GAZOLLA, M. Cadeias curtas e redes agroalimentares alternativas: negócios e mercados da agricultura familiar. Porto Alegre: Editora UFRGS, 2017. p. 129-145.

BRUNORI, G.; ROSSI, A.; MALANDRIN, V. Co-producing transition: innovation processes in farms adhering to Solidarity Purchase Groups (SGPS) in Tuscany, Italy. International Journal of Sociology of Agriculture and Food, v. 18(1), p. 28-53, 2011.

BROWN, P.; DAIGNEAULT, A.; DAWSON, J. Values, farming objectives, past management decisions, and future intentions in New Zealand. Journal of Environmental Management. v. 231, February 2019, p. 110-120.

CARROLL, B. E.; FAHY, F. Locating the locale of local food: the importance of context, space and social relations. Renewable Agriculture and Food Systems, v. 30(6), p. 563-576, 2015.

CASSOL, A. P. Redes agroalimentares alternativas: mercados interações e a construção da confiança. 2013. 186 f. Dissertação (Mestrado em Sociologia) - Universidade Federal do Rio Grande do Sul, Porto Alegre, 2013. 


\section{Gestãoe \\ Desenvolvimento}

e-ISSN: 2446-6875

p-ISSN: $1807-5436$

CASSOL, A. P.; SCHNEIDER, S. Produção e consumo de alimentos: Novas redes e atores. Lua Nova, São Paulo, 95: 143-177, 2015.

Construindo a confiança nas cadeias curtas: interações sociais, valores e qualidade na Feira do Pequeno Produtor de Passo Fundo/RS. In: SCHNEIDER, S.; GAZOLLA, M. Cadeias curtas e redes agroalimentares alternativas: negócios e mercados da agricultura familiar. Porto Alegre: Editora UFRGS, 2017. $520 \mathrm{p}$

CHIFFOLEAU, Y. From politics to co-operation: the dynamics of embeddedness in alternative food supply chains. Sociologia Ruralis, v. 49, n. 3, p. 218-235, 2009.

CONTERATTO, C. Agroindústria familiar: um estudo no município de Constantina-RS. 2017. 92 f. Monografia (Ciências Econômicas) - Universidade Federal de Santa Maria, Palmeira das Missões, 2017

COTEUR, I. et al. Structuring the myriad of sustainability assessments in agri-food systems: A case in Flanders. Journal of Cleaner Production, 209, 472-480, 2019.

DUARTE, S. C. L.; THOMÉ, K. M. Short food supply chain: estado da arte na academia brasileira. Estudos Sociedade e Agricultura, Rio de Janeiro, v. 23, n. 2, p. 315-340, 2015.

ESTATUTO DA ASSOCIAÇÃO DA FEIRA DOS PRODUTORES RURAIS DE PASSO FUNDO. Estatuto. Passo Fundo, 1996.

FERRARI, D. Cadeias agroalimentares curtas: a construção social de mercados de qualidade pelos agricultores familiares em Santa Catarina. 2011. 347f. Tese (Doutorado em Desenvolvimento Rural). Universidade Federal do Rio Grande do Sul, Programa de Pós-Graduação em Desenvolvimento Rural, Porto Alegre, 2011.

GOODMAN, D. The quality "turn" and alternative food practices: reflections and agenda. Journal of Rural Studies, v. 19, p. 1-7, 2003.

HAIR JR., J. F. Fundamentos de métodos de pesquisa em administração. Porto Alegre: Bookman, 2005.

HINRICHS, C. C. Embeddedness and local food systems: notes on two types of direct agricultural market. Journal of Rural Studies, v. 16, n. 3, p. 295-303, 2000.

HUBEAU, M. et al. A new agri-food systems sustainability approach to identify shared transformation pathways towards sustainability. Ecological Economics, 131, 2017, p. 52-63. 


\section{Gestãoe \\ Desenvolvimento}

e-ISSN: 2446-6875

p-ISSN: 1807-5436

JUNIOR, V. J. W.; TRENTIN, I. C. L. Agregação de valor e desenvolvimento sustentável nos municípios rurais. Revista Gestão e Desenvolvimento, Novo Hamburgo, v. 3, n. 2, aug. 2006.

MAIA, A. G.; BUAINAIN, A. M. O novo mapa da população rural brasileira. Confins, n. 25, 2015.

MARESCOTTI, A.; BELLETTI, G.; 'L'innovazione economica della filiera corta'. In: GIARÈ, F.; GIUCA, S. (Eds.). Agricoltori e filiera corta: Profili giuridici e dinamiche socio-economiche, p. 45-62, INEA, Roma, 2012.

MARSDEN, T.; BANKS, J.; BRISTOW, G. Food Supply Chain Approaches: exploring their role in rural development. Sociologia Ruralis. v. 40, n. 4, p. 424-438. 2000.

MALHOTRA, N. Pesquisa de marketing. 3a.ed. Porto Alegre: Bookman, 2001.

PERONDI, M. A.; RIBEIRO, E. M. As estratégias de reprodução de sitiantes no oeste de Minas Gerais e de colonos no sudoeste do Paraná. Organizações Rurais e Agroindustriais, Lavras, v. 2, n. 2, jul./dez., 2000.

RENTING, H.; MARSDEN, T.; BANKS, J. Understanding alternative food networks: exploring the role of short food supply chains in rural development. Environment and Planning, v. 35, p. 393-410, 2003.

ROCHA, H. C. et al. Perfil socioeconômico dos feirantes e consumidores da Feira do Produtor de Passo Fundo, RS. Ciência Rural [online], v. 40, n. 12, p. 2593-2597, 2010.

ROCHA, H. C.; COSTA, C.; CASTOLDI, F. L. Comercialização de produtos da agricultura familiar: um estudo de caso em Passo Fundo - RS. Revista de Administração IMED, v. 2(3), p. 151-157, 2012.

ROSSI, A. L'innovazione sociale della filiera corta. In: GIARÈ, F.; GIUCA, S. (Eds.). Agricoltori e filiera corta: Profili giuridici e dinamiche socio-economiche, p. 87-102, INEA, Roma, 2012.

ROSSI, A.; BRUNORI, G. Drivers of transformation in the agro-food system. GAS as co-production of Alternative Food Network. Paper for the $\mathbf{9}^{\text {th }}$ European EFSA Symposium, Vienna, 4-7 July, 2010.

ROSSI, A.; BRUNORI, G. As cadeias curtas de abastecimento na inovação nos dos Grupos de Aquisições solidárias (GAS): a construção social das práticas alimentares sustentáveis. In: SCHNEIDER, S.; GAZOLLA, M. Cadeias curtas e redes agroalimentares alternativas: negócios e mercados da agricultura familiar. Porto Alegre: Editora UFRGS, 2017. p. 83-103.

RUCABADO-PALOMAR T.; CUÉLLAR-PADILLA, M. Short food supply chains for local food: a difficult path. Renewable Agriculture and Food Systems, p. 1-10, 2018. 


\section{Gestãoe \\ Desenvolvimento}

e-ISSN: 2446-6875

p-ISSN: $1807-5436$

SAGE, C. Social embeddedness and relations of regard: alternative 'good food' networks in south-west Ireland. Journal of Rural Studies, v. 19, n. 1, p. 47-60, 2003.

SCARABELOT, M.; SCHNEIDER, S. As cadeias agroalimentares curtas de desenvolvimento local: um estudo de caso no município de Nova Veneza/SC. Faz Ciência. v. 14, n. 19. p. 101-130, Jan/Jun, 2012.

SCHNEIDER, S.; GAZOLLA, M. Cadeias curtas e redes agroalimentares alternativas: negócios e mercados da agricultura familiar. Porto Alegre: Editora UFRGS, 2017. 520 p.

SONNINO, R.; MARSDEN, T. K. Beyond the divide: Rethinking relationships between alternative and conventional food networks in Europe. Journal of Economic Geography, v. 6(2): 181-199, 2006.

SPANEVELLO, R. M. et al. A problemática do envelhecimento no meio rural sob a ótica dos agricultores familiares sem sucessores. Desenvolvimento em Questão, 15(40), 2017.

STRATE, M. F.; CONTERATO, M. A. Agroindustrialização e arranjos produtivos locais como estratégia de diversificar e fortalecer a agricultura familiar no RS. Guaju, Matinhos, v. 4, n. 2, p. 48-62, 2018.

TRIVETTE, S. Invoices on scraps of paper: trust and reciprocity in local food systems. Agriculture and Human Values, Dordrecht, v. 34, n. 3, p. 529-542, 2017.

WILKINSON, J. Mercados, redes e valores: o novo mundo da agricultura familiar. Porto Alegre: Editora da UFRGS: Programa de Pós-Graduação em Desenvolvimento Rural, 2008.

WRIGHT, W.; BROWN, P. Succession and investment in New Zealand farming. New Zealand Economic Papers, Volume 53, edição 2, 2019. Disponivel em: <https://doi.org/10.1080/00779954.2017.1419501 >. Acesso em: 09 nov. 2018. 